\title{
La metamorfosis de una economía agraria en la pampa argentina. Buenos Aires y Santa Fe entre las décadas de 1850 y 1890
}

\author{
The Transformation of an Agrarian Economy \\ in Argentine Pampa. Buenos Aires and Santa Fe \\ between the 1850 s and 1890 s
}

\author{
María Fernanda Barcos \\ Orcid iD: http://orcid.org/0000-0002-7698-8284 \\ Universidad Nacional de La Plata / CONICET \\ Juan Luis Martirén \\ Orcid iD: http://orcid.org/0000-0002-0826-2879 \\ Universidad de Buenos Aires / CONICET
}

El trabajo analiza la evolución de las economías agrarias de dos provincias del área pampeana entre las décadas de 1850 y 1890, un período clave para la transformación agrícola argentina. El objetivo central es proponer una mirada comparativa entre Buenos Aires y Santa Fe, que permita examinar las distintas etapas y las características diferenciales que tuvo el desarrollo de la agricultura pampeana hasta transformarse en una de las principales actividades económicas en el cambio de siglo. Los casos presentados buscan evidenciar cómo los ensayos de colonización agrícola santafesina lograron asentar una receta productiva de agricultura extensiva que desplazaría no solo a las tradicionales formas de producción agraria bonaerense, sino que también competiría con su dinámica producción ganadera.

Palabras Clave: Argentina; Región Pampeana; Agricultura; Colonización Agrícola; Ejidos; Siglo XIX.

The paper focuses on the divergent evolution of two agrarian economies in Argentine pampas between the decades of 1850 and 1890. Through a comparative exercise of Buenos Aires and Santa Fe provinces, the paper tries to show the stages and the particular characteristics that addressed the development of Pampean agriculture expansion till the turn of the century. We assume that farming agriculture in Santa Fe succeeded to expand a productive recipe of extensive agriculture that would displace not only the traditional forms of agricultural production in Buenos Aires, but also compete with its dynamic livestock production.

KEywords: Argentina; Pampean Region; Agriculture; Agricultural Colonization; Ejidos; XIX Century.

Copyright: (C) 2019 CSIC. Este es un artículo de acceso abierto distribuido bajo los términos de la licencia de uso y distribución Creative Commons Reconocimiento 4.0 Internacional (CC BY 4.0). 


\section{Introducción}

La fuerte expansión desarrollada por la economía agraria pampeana durante la segunda mitad del siglo XIX conllevó gran atención de la historiografía. Numerosos trabajos han planteado de manera clara las particularidades de las provincias de Buenos Aires y Santa Fe y el rol fundamental que cada una de ellas ejercieron sobre el crecimiento logrado por la agricultura argentina durante el período. ${ }^{1} \mathrm{Si}$ bien se conoce mejor el periodo que transcurre entre 1895 y 1914 —gracias a la existencia de los censos agrícolas y económicos de 1895, 1908 y 1914—, existen aún varios interrogantes sobre las características de la evolución agraria entre las décadas de 1850 a 1890, momento central en el cual se abrieron diferentes caminos que terminaron provocando la transformación de la sociedad y la economía del país.

Para indagar esta cuestión general, nos proponemos estudiar comparativamente las provincias de Santa Fe y Buenos Aires durante la segunda mitad del siglo XIX. El objetivo es por demás ambicioso ya que mucho se ha dicho al respecto. ${ }^{2}$ Sin embargo, buscamos exponer aquí nuevas hipótesis a partir del análisis comparativo. Apelamos para ello a cuatro estudios de caso (tres para representar a la provincia de Buenos Aires, y uno para Santa Fe) que por sus particulares características resultan útiles para desarrollar los objetivos propuestos. Si bien lo ideal sería contar con estadísticas completas para ambas provincias, la escasez de datos comparables para las décadas de 1850 a 1870 nos obliga a presentar un análisis acotado a los dos principales nichos de producción agraria de cada espacio. ${ }^{3}$ Así, para

1 El área pampeana argentina es una región de fértiles llanuras ubicadas en el centro-este del país, en parte de lo que actualmente son las provincias de Buenos Aires, Santa Fe, Córdoba, Entre Ríos y La Pampa. En el siglo XIX, una porción de esta región también fue conocida como Litoral y comprendía un área mucho más limitada en torno a los dos grandes ríos que la surcan, el Paraná y el Uruguay. Hacia fines de siglo, con la expansión de las fronteras internas ya consolidada, comenzó a ser identificada como región o área pampeana, término que se utiliza hasta la actualidad.

2 Los estudios sobre la expansión agrícola pampeana de la segunda mitad del siglo XIX han tenido amplio desarrollo. Algunos balances historiográficos han dado cuenta de ello: Míguez, 1986 y 2006. Estudios más recientes en Barsky y Gelman, 2009; Djenderedjian et al., 2010; Hora, 2010.

3 Cabe destacar que la división administrativa del territorio de ambas provincias tuvo algunas diferencias. Santa Fe fue dividida en departamentos, esto es, unidades territoriales que solo tenían una función electoral o estadística. Allí cada colonia, pueblo o ciudad tenía su administración, que podía ser municipal, por medio de juzgados de paz o bien mediante dependencias de distritos mayores. En Buenos Aires, en cambio, cada distrito se denominaba «partido», que contaba con su propia administración. 
Buenos Aires analizaremos dos partidos del oeste provincial (Chivilcoy y Mercedes) y un núcleo agrícola del norte (Baradero), en los cuales se practicó agricultura pero en diferentes escalas: colonia, ejido y campo. ${ }^{4}$ Para el caso santafesino estudiaremos el núcleo primigenio de colonización agrícola emplazado en el centro de la provincia (que desde 1883 estaría englobado en el departamento Las Colonias). ${ }^{5}$

Se buscan analizar de este modo las características particulares de cada economía agraria a lo largo del período analizado. El trabajo se dividirá en dos partes: por un lado, nos enfocaremos en el preludio de la gran expansión agraria entre las décadas de 1850 y 1870, momento en el que Buenos Aires y Santa Fe presentaban un claro contraste. La primera se orientaba a la agricultura ejidal y «a campo», en convivencia con importantes - y más modernos- establecimientos ganaderos; Santa Fe, en cambio, experimentaba un modelo de producción novedoso, guiado por la transformación racional del espacio mediante la implantación de colonias agrícolas, pero que al mismo tiempo también competía y convivía con una sociedad criolla que funcionaba bajo pautas de producción ganadera tradicional. Se trata de un período que aun presenta ciertos claroscuros, por lo que se buscan dilucidar las razones por las cuales las colonias de Santa Fe siguieron un derrotero productivo marcado por la expansión constante de sus unidades de explotación gracias a niveles crecientes de inversión en tecnología, y los partidos de Buenos Aires se especializaron en la producción pecuaria de alta capitalización, dejando en un segundo plano la producción cerealera que habían alcanzado hasta el momento.

En la segunda parte del trabajo se pondrá el foco en las dos últimas décadas del siglo, cuando el modelo de agricultura extensiva logró solidificar su receta y expandirse desde Santa Fe hacia otras regiones del área

4 Los ejidos a los que nos estamos refiriendo eran las tierras que rodeaban a los centros poblados y que estaban destinadas por ley a establecer población y cultivo «exclusivamente», puesto que no se permitía allí el pastoreo. Estas tierras se dividían en solares, quintas y chacras, con un rango de superficies que oscilaban entre 7 y 54 hectáreas. Todas las prácticas agrícolas llevadas a cabo en ese espacio han sido agrupadas bajo el rótulo de «agricultura ejidal». Pero en paralelo también existió en la provincia de Buenos Aires otro tipo de agricultura, de carácter más extensivo, llamada «agricultura a campo». Se desarrollaba en general sobre unidades denominadas chacras, que tenían una extensión mayor a las ejidales, en el orden de las 150 y 200 hectáreas. Allí el cultivo del cereal era predominante respecto de la frutihorticultura dominante en las unidades ejidales.

5 El espacio de colonización primigenio comenzó con la instalación de tres colonias a mediados de la década de 1850, aunque fue en constante expansión durante el período analizado, llegando a 23 colonias en 1881. Sobre este espacio, ver Gallo, 1983; Djenderedjian et al., 2010; Martirén, 2016. 
pampeana, entre ellas, Buenos Aires. A partir de la evidencia presentada en los censos de 1881, 1888 y 1895, buscaremos mostrar las características de la nueva agricultura bonaerense y las bases de su crecimiento. Si bien continuaremos con el análisis de los estudios de caso elegidos, adicionaremos las estadísticas totales de cada provincia, en tanto permiten presentar un panorama más completo de cada realidad agraria.

La hipótesis que guiará nuestra investigación supone que el proceso de transformación de la agricultura pampeana tuvo su origen principalmente en las colonias agrícolas santafesinas durante las décadas de 1860 y 1870 . Destaca que mientras los partidos de Buenos Aires reconfiguraron su tradicional agricultura ejidal y extensiva al perder espacio frente a la presión urbana y una economía ganadera más dinámica y capitalizada, las colonias lograron replicar su modelo productivo sin tener que competir en términos de rentabilidad con la actividad ganadera. En otras palabras, la base familiar de las colonias agrícolas — que atenuaba el alto costo del factor trabajo en una actividad con mano de obra intensiva - sumada a la abundancia del factor tierra, que permitía el acceso a terrenos de bajo precio cercanos a los centros de comercialización y a un mercado crediticio orientado a financiar el acceso al capital productivo de pequeños y medianos productores (sobre todo en maquinarias e insumos), permitió el desarrollo de una receta productiva que para 1880 ya estaba consolidada. En Buenos Aires, en cambio, el polo agrícola que se había formado en el oeste entre las décadas de 1850 y 1860 perdió peso relativo ante el gran crecimiento que experimentó la ganadería ovina. Esta no solo afectó el coste de los factores (y por tanto a la economía «a campo» o extensiva que allí se practicaba, que comenzó a orientarse hacia el ovino), sino también promovió el crecimiento de los centros urbanos, que presionaron al alza los precios de la tierra en los ejidos, lo que los llevó a encaminarse definitivamente hacia actividades diversificadas (horticultura, lechería, entre otras).

Siguiendo este postulado, buscaremos mostrar entonces dos realidades diferentes. Por un lado, los vaivenes que debió atravesar la agricultura bonaerense, con su gran crecimiento en las décadas de 1850 y 1860 , su freno en la década de 1870, y su posterior crecimiento en las décadas de 1880 y 1890. Por el otro, el proceso de emergencia, experimentación y consolidación de la agricultura extensiva santafesina, motorizada por el proceso de colonización agrícola. 


\section{Buenos Aires y Santa Fe en el exordio de la gran expansión: dos modelos de producción agraria}

Al promediar la década de 1810, el crecimiento de la población de la campaña de Buenos Aires era ya sostenido. La expansión económica que la orientación atlántica de la economía de la región había iniciado en ese momento generó atracción de importantes flujos de inmigrantes de otras provincias, que se instalaron progresivamente en un área delimitada por el Río Salado, el Arroyo del Medio y el Río de la Plata. ${ }^{6}$ De todos modos, la distribución de la población no había sido homogénea, pudiéndose diferenciar cuatro zonas: periurbana (en torno a la ciudad de Buenos Aires), norte, oeste y sur. Según esta clasificación, los actuales partidos de Chivilcoy y Mercedes se encontraban en la región oeste, mientras que el de Baradero era parte del norte provincial.

Destacar esta división geográfica resulta importante, ya que tuvieron grandes diferencias productivas. Las zonas periurbanas, caracterizadas por la presencia mayoritaria de labradores, tenían desde el período tardocolonial una considerable producción cerealera, aunque para mediados del siglo habían comenzado a orientarse hacia la horticultura. ${ }^{7}$ La región norte, por su parte, había logrado un gran dinamismo tanto en términos productivos como demográficos debido a su posicionamiento estratégico. ${ }^{8} \mathrm{Y}$ para mediados del siglo, había logrado desarrollar una rica economía ganadera en varios de sus partidos, entre ellos el de Baradero, donde también se estableció una colonia de inmigrantes suizos con la intención de promover la agricultura. Este emprendimiento quedó formalmente establecido el 4 de febrero de 1856 mediante diversas donaciones efectuadas por la municipalidad a familias extranjeras recién llegadas y sobre terrenos ejidales. ${ }^{9}$

6 Es de destacar que en la campaña, dividida por entonces en 24 partidos, habitaban casi 43.000 personas. Sobre este proceso ver, entre otros, GIHRR, 2004, 21-63.

7 Sobre este tema, ver Ciliberto, 2004; Garavaglia, 1993.

8 Para mediados del siglo XIX, el norte provincial tenía una marcada impronta ganadera, acompañada de una limitada producción agrícola centrada mayormente en tierras ejidales. Según el registro estadístico de 1855, de las casi 1.200.000 hectáreas que abarcaban los partidos del norte, solo 28.000 estaban ocupadas por labradores, es decir, el 2,4\%. En el caso de Baradero, que tomamos para analizar esta región, de 135.000 hectáreas solo 2.700 estaban en manos de agricultores. Ver Estado de Buenos Aires, 1855, 13.

9 La idea de los funcionarios municipales era promover la agricultura en el partido, por lo que cedieron las tierras a título gratuito poniendo como requisito la necesidad de practicar labores agrícolas. Dado que luego de instalado el primer grupo de colonos provenientes de Friburgo, continuaron llegando familias, la corporación municipal siguió entregando lotes pero al sur del pueblo y sobre terrenos otorgados en enfiteusis. Para 1864, la colonia estaba poblada por 837 individuos entre 
En la región oeste, donde se encontraban los partidos de Mercedes y Chivilcoy, la economía también alcanzó un amplio desarrollo en la primera mitad del siglo XIX. Allí la actividad productiva había sido tradicionalmente mixta, pero a partir de mediados de la centuria estos distritos tomaron caminos diferentes, lo que convierte a ambos casos en un mirador interesante para entender las diferencias en el seno de una misma región. Mercedes se fue orientando más decisivamente a la cría de ovinos, convirtiéndose en uno de los principales núcleos ganaderos y a la vez mercantiles de la provincia. Allí, las prácticas agrícolas, como en la mayoría de los pueblos de la campaña bonaerense, se realizaban en los ejidos (sobre lotes de hasta 7 hectáreas para quintas y 54 hectáreas para chacras, aunque varios de ellos se explotaban juntos) y estaban basadas fundamentalmente en actividades frutihortícolas y cerealeras para el abasto local. ${ }^{10}$ En Chivilcoy el esquema productivo tenía, por el contrario, una clara impronta agrícola; allí la tierra fue inicialmente ocupada por miembros de antiguas familias que, al carecer de terrenos en otros partidos de más antigua ocupación —o bien como mecanismo para diversificar su patrimonio- se adentraron a la frontera en tierras públicas otorgadas bajo la modalidad de enfiteusis. Este sistema, que implicaba la entrega de tierras públicas a privados a cambio de un canon en dinero, ya estaba en desuso para la década de 1850, y quienes aun continuaban ocupando las tierras bajo este régimen dejaron de pagar la contraprestación monetaria o bien abonaban sumas irrisorias. Se trataba de «propietarios» con derechos de propiedad endebles que, sin embargo, cobraban sub-arrendamiento a otros ocupantes. Para tener una cabal idea de la dimensión del problema: a mediados de la década de 1850 había en Chivilcoy 885 arrendatarios ubicados en tierras de 18 enfiteutas, la mayoría de ellos absentistas. Esta situación incluía alrededor de la mitad del territorio total del partido donde justamente se practicaba la agricultura. Los arrendatarios, mayoritariamente criollos, fueron los que convirtieron a Chivilcoy en el principal distrito cerealero de la campaña de Buenos Aires; aunque desde luego la situación mencionada generaba profundo

suizos, franceses y alemanes. Fuera de ella, en el ejido vivían también franceses, vascos e italianos dedicados a la agricultura y horticultura, por tanto la actividad productiva se organizaba en estos dos nichos que convivieron también con ganadería ovina. Baradero permaneció con la misma superficie hasta que fueron fijados sus límites en 1865. Más información sobre el devenir de este distrito en: República Argentina, 1865, 94; Ford, 1867, 58-59; Sociedad Agrícola de Baradero, 1882; Salaberry, 2009; Djenderedjian et al., 2010.

10 Un análisis específico de este distrito en Barcos, 2013 y 2018. 
malestar entre ellos puesto que no tenían garantizados sus derechos de propiedad. ${ }^{11}$

En síntesis, hacia 1860 la campaña de Buenos Aires tenía una división territorial con características productivas específicas. A grandes rasgos podría decirse que en las tierras periurbanas al mayor centro de abasto (Buenos Aires), predominaban unidades productivas menores a 2 hectáreas, donde se desarrollaba sobre todo horticultura y agricultura cerealera. En el norte, por su parte, más allá de una considerable producción de maíz, se estaba expandiendo con gran fuerza la ganadería ovina, que iría creciendo progresivamente desde la década de 1860. Esta actividad se expandió también — aunque más tardíamente- en los distritos del sur, caracterizados por un claro corte pecuario en unidades productivas de mayor extensión

\section{TABLA 1}

POBLACIÓN Y PRODUCCIÓN AGROPECUARIA DE LA CAMPAÑA BONAERENSE EN 1855

\begin{tabular}{|l|c|c|c|c|c|c|c|c|c|}
\hline \multirow{2}{*}{ Región } & \multirow{2}{*}{ Población } & \multirow{2}{*}{$\begin{array}{c}\text { Extensión } \\
\text { (ha) }\end{array}$} & $\begin{array}{c}\text { Trigo } \\
\text { (tn) }\end{array}$ & $\begin{array}{c}\text { Maíz } \\
(\text { tn })\end{array}$ & $\begin{array}{c}\text { Papas } \\
\text { (tn) }\end{array}$ & $\begin{array}{c}\text { Ganado } \\
\text { vacuno } \\
\text { en pie }\end{array}$ & $\begin{array}{c}\text { Ganado } \\
\text { lanar } \\
\text { en pie }\end{array}$ & $\begin{array}{c}\text { Lana } \\
\text { (tn) }\end{array}$ & $\begin{array}{c}\text { Cueros } \\
\text { vacunos }\end{array}$ \\
\hline Periurbano & 31.732 & 268.650 & 1.651 & 352 & 601 & 18.799 & 10.448 & 234 & 24.090 \\
\hline Norte & 32.347 & 1.383 .750 & 42 & 79 & 14 & 53.797 & 21.447 & 409 & 32.595 \\
\hline Oeste & 50.676 & 3.018 .600 & 1.065 & 313 & 4 & 37.111 & 30.099 & 843 & 48.708 \\
\hline Sud & 62.305 & 7.168 .500 & 68 & 242 & 25 & 132.742 & 45.717 & 1.005 & 103.332 \\
\hline
\end{tabular}

Fuente: Elaboración propia basada en Estado de Buenos Aires, 1855, 11 y tabla 14.

11 El problema se volvió significativo, tanto que 360 labradores presentaron en 1854 un petitorio ante la Cámara de Representantes quejándose de la situación y pidiendo se suspendieran los derechos que amparaban a los enfiteutas. El gobierno se hizo eco de la situación y el mismo año dictó un decreto suspendiendo el pago de sub arrendamiento en tierras que volvieron a ser fiscales. Finalmente, en 1857 se sancionó una ley específica para este partido, que ordenaba la enajenación de las enfiteusis que estaban en discusión y la división de estas en manzanas de 40 cuadras por lado. Se acordó que los ocupantes tendrían derecho a conservar la posesión pagando un tercio del valor del lote al momento de adjudicarse y el resto a plazo. Los lotes que no se encontraban ocupados podrían venderse en remate. También había límites en el número de lotes adquiridos por una persona. Luego de sancionada esta ley, y a pesar de los vericuetos para escriturar, que originaron decretos reglamentarios, los labradores de Chivilcoy se encontraron en una situación ventajosa en relación con el resto de los partidos y con mayores garantías para la propiedad, cuestión que debió ser una ventaja extraeconómica a tener en cuenta. 
en promedio. En el oeste, por lo demás, la ganadería ovina también ganaba lugar, aunque la producción de cereales había logrado instalarse y convivir con la ganadería. ${ }^{12}$

El desarrollo agrario santafesino, por su parte, tuvo un derrotero bien diferente. Al promediar el siglo XIX, el panorama productivo rural presentaba un claro contraste con el bonaerense. ${ }^{13}$ No solo el importante stock ganadero que había ostentado entre fines del siglo XVIII y principios del XIX no había podido recuperarse luego de los estragos causados por las guerras de la década de 1820, sino que el espacio efectivamente ocupado era muy limitado. ${ }^{14}$ Entre varias medidas tendientes a fomentar políticas de expansión territorial y de ocupación del espacio allende a esas limitadas fronteras, se instalaron colonias agrícolas con inmigrantes europeos que se convirtieron desde 1856 en la punta de lanza para la puesta en producción de aquellas tierras yermas. Estos emprendimientos, contemporáneos a los de la mencionada colonia de Baradero, tuvieron en Santa Fe una evolución totalmente distinta. Supusieron, además, un cambio radical: en primer lugar, porque estaban pensadas para modificar la ecuación factorial imperante. Es decir, poner en producción un recurso abundante (la tierra) mediante la incorporación de otros dos que eran escasos (mano de obra y capital). En segundo lugar, porque más allá de los objetivos generales, las colonias serían útiles no solo para ampliar la ocupación de tierras, sino también como reaseguro de las líneas de frontera. ${ }^{15} \mathrm{Y}$ en tercer lugar, porque implicarían un cambio fundamental: por primera vez se buscaba modificar el territorio mediante la implantación racional de un modelo de producción agrícola, que traería aparejadas múltiples mudanzas, desde nuevas concepciones de

12 Lamentablemente los datos estadísticos disponibles para la provincia de Buenos Aires entre las décadas de 1850 y 1870 no permiten calcular superficie sembrada ni producción por distritos. El problema se debe a que si bien existe información para una gran cantidad de años en ese período, no siempre hay datos para todos los partidos, o bien cuando para algunos se conocen datos de producción, en otros hay solo información sobre superficie sembrada y viceversa. Esto hace imposible reunir en una sola tabla los datos más importantes que reflejan el estado de la agricultura en un determinado espacio.

13 Frid, 2007.

14 Gallo, 1972. Como podrá notarse en el mapa 1, la línea de frontera hacia 1862 solo se extendía por una estrecha franja del territorio actual de la provincia.

15 Más allá de algunas experiencias de colonización fracasadas, desde fines del periodo colonial la ocupación oficial del territorio en Buenos Aires se había efectuado bajo la modalidad de fundación de pueblos a la usanza española. Estos incluían un espacio circundante dedicado a establecer cultivos (denominado «tierras de pan llevar»). Esta modalidad no incluía la parcelación de predios ni tampoco se prestó especial atención al factor migratorio europeo. 
derechos de propiedad a modelos de organización institucional inexistentes en ese momento en la campaña santafesina. ${ }^{16}$

Se trataba entonces de dos realidades desiguales sobre las cuales la economía agraria pampeana comenzaría a transformarse. En materia agrícola, y sobre todo en Santa Fe, se daría inicio a un proceso de mecanización de las prácticas agrícolas que iría cambiando el paquete tecnológico imperante. Paralelamente, se asistiría a una rápida expansión de la ganadería ovina, que se convertiría en un factor de fuerte competencia sobre la tradicional producción agrícola de los partidos de Buenos Aires. Teniendo en cuenta esa cuestión, buscaremos analizar a continuación las raíces y la evolución de dichos cambios, con la intención de profundizar las explicaciones sobre los distintos derroteros de la agricultura en el área pampeana previos a la gran expansión.
MAPA 1

UBICACIÓN DE LAS COLONIAS SANTAFESINAS Y LOS PARTIDOS BONAERENSES EN 1862

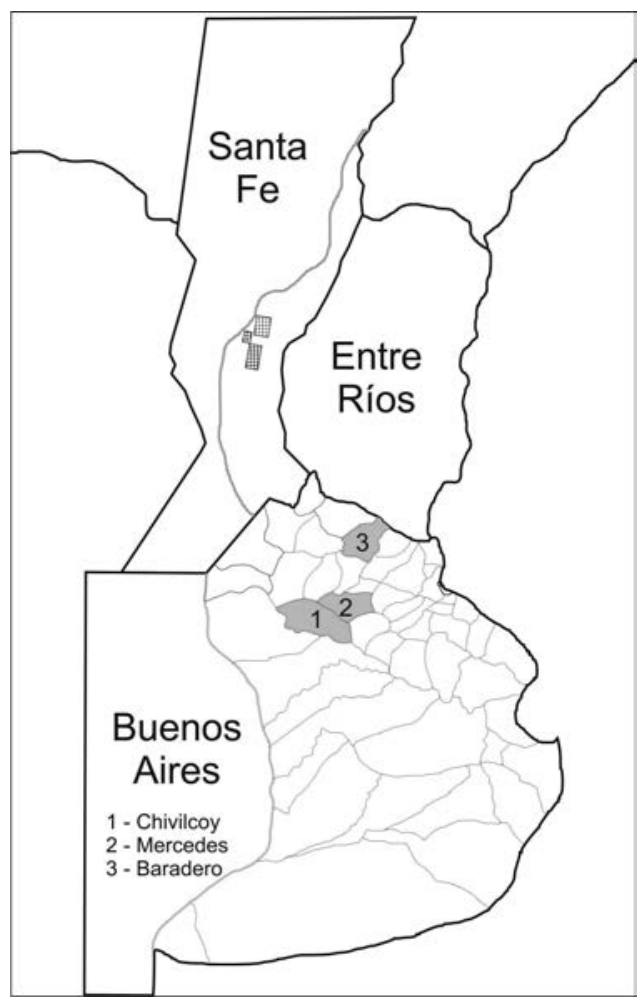

Fuente: Elaboración propia basada en Carrasco (1888) y Álvarez de Arenales (1862).

\section{Dos caminos diferentes}

Para fines de los años sesenta, como dijimos, el auge de la ganadería lanar estaba modificando en gran medida la producción agraria de Buenos Aires. A nivel provincial, el área de cría de este animal se expandía

16 Martirén, 2014. 
gradualmente por toda el área efectivamente ocupada, que aun tenía importantes constricciones territoriales hacia el oeste, tal como puede apreciarse en el mapa 1. Este proceso, conocido en la historiografía como «fiebre del lanar», comenzaría a generar cambios significativos en la economía y sociedad de la campaña. ${ }^{17}$

¿Cómo era la agricultura bonaerense en el momento previo a la gran expansión que tendría inicio en la década de 1880 ? Básicamente, se había desarrollado sobre dos modalidades: ejidal y «a campo». Desde fines del período colonial, la producción ejidal había adquirido un importante desarrollo en Mercedes gracias al establecimiento de familias labradoras - muchas de ellas donatarias - en quintas y/o chacras. En paralelo, se habían adjudicado, también desde la misma época, varios terrenos para estancias ganaderas que abarcaban grandes extensiones, aun siendo este un partido con predominio de la propiedad subdividida. Estas unidades fueron explotadas por medieros, arrendatarios y propietarios (criollos pero también muchos de ellos europeos), que utilizaban mano de obra familiar y asalariada. El crecimiento de este esquema supuso la práctica de una agricultura tradicional en el ejido y una ganadería pujante en las estancias, que tenían como constante una fuerte presión sobre la tierra, puesto que para las primeras décadas del siglo XIX la mayoría del partido estaba ya ocupado. La privatización de la tierra en este partido se dio tempranamente y provocó un encarecimiento de ese factor, al que se sumó el crecimiento poblacional de la primera mitad del siglo XIX. De ese modo, la necesidad de tierras condujo al avance de la frontera allende al río Salado hasta llegar a las tierras de Chivilcoy, tal como explicamos en el apartado anterior. Allí el esquema productivo que se desarrolló fue diferente al mercedino, porque además de la ganadería ovina, se impulsó una dinámica producción agrícola que se llevó a cabo a campo abierto y fundamentalmente en chacras de mayores dimensiones que las ejidales. Los efectos se vieron rápidamente: para 1855, a poco tiempo de su fundación, Chivilcoy ya había logrado alcanzar importantes niveles de cultivos y se posicionaba como el principal nicho agrícola de la campaña de Buenos Aires. ${ }^{18}$

Con la llegada del ferrocarril a Mercedes en 1864, y su extensión hasta Chivilcoy en 1866, este último partido logró expandir aun más sus

17 Sobre el proceso de crecimiento de la ganadería lanar en Buenos Aires entre las décadas de 1840 y 1880 ver, entre otros, Sábato, 1989; Barsky y Djenderedjian, 2003.

18 Según el Registro Estadístico de 1855, Chivilcoy tenía sembradas ese año algo más de 10.000 hectáreas de trigo. Estado de Buenos Aires, 1855, 10. 
sementeras, lo que terminó asentando claramente los dos sistemas de producción agrícola mencionados. Por un lado, la frutihorticultura como actividad principal, combinada con el cultivo de trigo o maíz en la zona de quintas y chacras ejidales. ${ }^{19}$ Por otro, el sistema de agricultura «a campo», en el cual se empleaban varias mejoras técnicas que redundaron rápidamente en un aumento de la escala productiva, sobre todo mediante ensayo y error ${ }^{20} \mathrm{El}$ rasgo más notable de esta modalidad fue el aumento del tamaño de las sementeras a 200 hectáreas, ampliación motorizada sobre todo por los medianos productores que ocupaban más de dos tercios del total de explotaciones. $^{21}$

Los dispersos datos disponibles mostrarían, sin embargo, que más allá de la presunta extensión de la escala productiva lograda por estas mejoras, el crecimiento de la agricultura chivilconiana no habría sido lineal (algo que sí se dio en la agricultura santafesina). Los datos existentes para las décadas de 1850 y 1860 muestran una creciente producción de los cultivos de trigo, y en ello sin dudas el peso del ferrocarril debió haber sido fundamental en tanto permitió abaratar los fletes y dinamizar los circuitos de comercialización con respecto al principal centro de abasto. ${ }^{22}$ No obstante, y a juzgar por el crecimiento del stock ovino, todo parece indicar que el ferrocarril habría beneficiado aun más a la ganadería ovina, cuyo mejor costo de oportunidad pareció impulsar su crecimiento relativo y desde luego frenar una mayor expansión de la agricultura.

19 Eran unidades de producción más pequeñas, impulsadas por un mayor rendimiento por hectárea, el autoconsumo familiar y las necesidades de abasto del pueblo. Estas actividades se desarrollaron con una tecnología precaria y muy distinta a la que sobrevendía desde la década de 1860 . Sobre este aspecto, ver Djenderedjian, 2008.

20 Andreucci, 2011.

21 Garavaglia, 2004. Según Andreucci, los productores de Chivilcoy se presentaron como personajes dinámicos preocupados por mejorar las prácticas agrícolas, incorporando maquinaria y generando circuitos de comercialización (acopio). Andreucci, 2011.

22 Según datos del Registro Estadístico de la República Argentina, hacia 1864 había en Chivilcoy casi 18.500 hectáreas de trigo sembrado y 9.500 de maíz, habiendo alcanzado una extracción de aproximadamente 25.250 toneladas de dicho cereal ese año. Si bien no podemos saber si la extracción correspondía solo a Chivilcoy o si allí se acopiaba también parte de la producción de distritos vecinos, está claro que las salidas de trigo desde ese distrito se consolidaron con el ferrocarril. De todos modos, y a pesar de que continuaron teniendo un peso fundamental en los envíos de trigo a los mercados de Buenos Aires en la década de 1870, los partidos del oeste (en particular Chivilcoy) parecen haber tenido un leve descenso en su producción, a juzgar por los datos de extracción de trigo correspondientes a la década de 1870. La información recabada de los registros estadísticos establece las siguientes cifras: 15.974 toneladas en $1872,5.543$ en 1873 y 13.725 en 1874. Ver: República Argentina, 1865, 219; Provincia de Buenos Aires, 1874, 281; Provincia de Buenos Aires, 1875, 274; Provincia de Buenos Aires, 1876, 376. 


\section{GRÁFICO 1}

\section{EVOLUCIÓN DE LOS STOCKS GANADEROS EN BARADERO, CHIVILCOY Y MERCEDES, 1855-1881 (EN CABEZAS DE GANADO)}

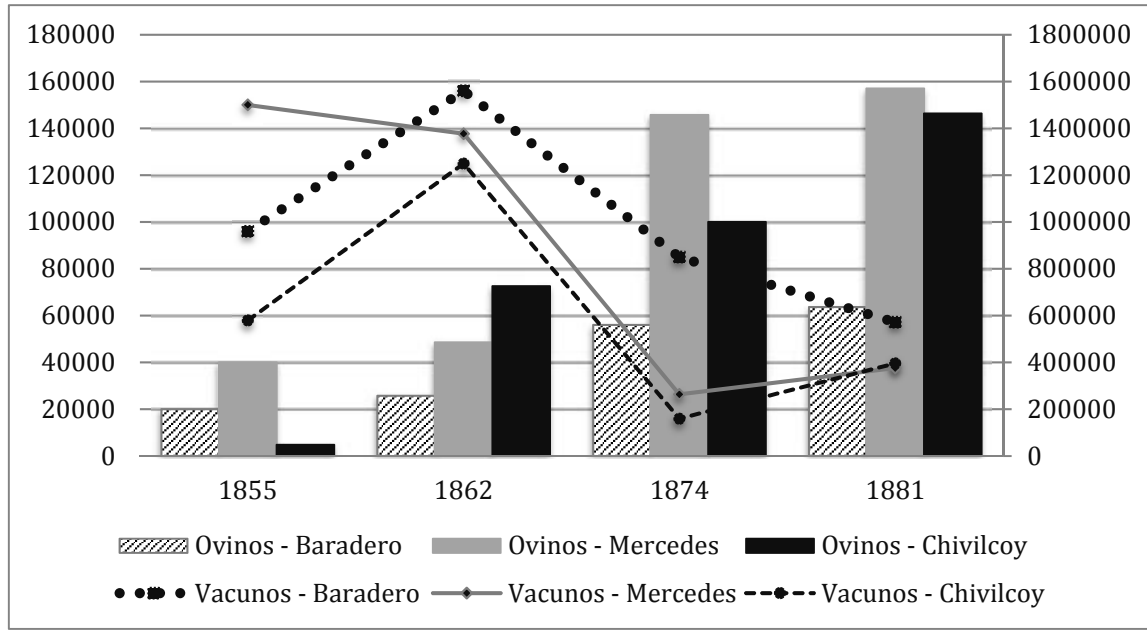

Fuente: Elaboración propia basada en: Estado de Buenos Aires (1855); Provincia de Buenos Aires (1864, 1875 y 1883); República Argentina (1865); Mulhall (1876).

Si a esta situación de estancamiento se le agregan los datos de crecimiento de la ganadería, el panorama es evidente. Chivilcoy es el distrito que más sorprende, ya que en 1881 pastaban en su territorio más de 1.400 .000 ovinos; es decir, casi el doble de las existencias de 1862. Ello no sería llamativo si no fuese porque la extensión de cultivos de cereales declarada en 1881 apenas superaba las 10.000 hectáreas, una cifra muy modesta para el principal distrito agrícola de la campaña, incluso menor a la de las décadas de 1850 y 1860 . Esta información da cuenta así de un fenómeno ya conocido por la historiografía; es decir, que el gran dinamismo de la producción ovina presentaba un costo de oportunidad mucho más alto que el de la agricultura, lo que habría frenado su avance, por lo menos hasta la década de $1880 .^{23}$

En Mercedes esta situación era de suponerse, pues la agricultura ya había pasado a tener un lugar secundario en relación a la ganadería desde

23 Una detallada explicación de este fenómeno en Djenderedjian et al., 2010, 675 y ss. 
hacía bastante tiempo. A mediados de la década de 1860, precisamente cuando llegó a la región el ferrocarril, el lanar era la actividad más dinámica y a su vez continuaba expandiéndose. De todos modos, ello no significó que la agricultura ejidal no haya sido una opción viable. Así se desprende de las quejas de los productores hortícolas de ese partido respecto del avance de los lanares sobre el anillo externo del ejido, que era el que contenía a las chacras. Es más, en las encuestas que originaron la confección del primer Código Rural de la Provincia de Buenos Aires (1865), este fue uno de los principales problemas que se trató. Su autor, Valentín Alsina, se preguntaba: «¿sería factible rodear a los ejidos de una zona intermedia de ganado menor (ovino) y que el ganado mayor (vacuno y caballar) solo pueda tolerarse fuera?». ${ }^{24}$ Más allá de algunas medidas tenientes a solucionar dicho problema, la presencia del lanar se haría aun más importante en la década siguiente.

Baradero, por lo demás, también parece haber atravesado una amplia expansión de la ganadería, pese a que se había desarrollado allí desde 1856 una colonia agrícola. Este caso es interesante, pues refleja claramente las dificultades que debían enfrentar estos establecimientos orientados al fomento de la agricultura para consolidarse. Básicamente necesitaban un bajo costo del factor tierra, algo que no ocurría en ese distrito. Al igual que en Santa $\mathrm{Fe}$, Baradero se organizó racionalmente como una colonia agrícola y se fomentó su poblamiento mediante la instalación inicial de inmigrantes europeos. Sin embargo, su organización territorial quedó rápidamente limitada, ya que los terratenientes lindantes arrendaron sus campos generando un corsé alrededor del ejido. Esto fue minando las posibilidades de expansión de las sementeras. Los datos que tenemos para 1868, 1869 y 1870 reflejan magros resultados en términos de agricultura cerealera (sobre todo en trigo, que no superaba las 400 toneladas anuales, aunque un poco más considerable en maíz) y una mayor impronta hortícola. ${ }^{25}$ Por su parte, y a juzgar por los datos expuestos en el gráfico precedente, en el resto del partido el ovino creció ininterrumpidamente durante el período.

24 Valentín Alsina, Mensaje y Proyecto de Ley del Código Rural para la provincia de Buenos Aires, Archivo Histórico de la Provincia de Buenos Aires, Cámara de Senadores, leg. 30, 1865.

25 Beck, 1872, 113. Este problema no se dio en Santa Fe, donde los terratenientes linderos sí destinaron sus tierras a la colonización o bien las enajenaron a otros empresarios colonizadores. Sin duda, allí la ganadería ovina no tenía el desarrollo logrado por Buenos Aires, por lo que la agricultura en colonias era tal vez el principal rubro a desarrollar (además de una tradicional ganadería de baja rentabilidad). Sobre este punto, ver Martirén, 2016, cap. 4. 
GRÁFICO 2

PRECIOS DE LA LANA, EL TRIGO Y EL MAÍZ DE CALIDAD DE EXPORTACIÓN EN ARGENTINA DURANTE LA DÉCADA DE 1870 (VALORES EXPRESADOS EN PESOS ORO)

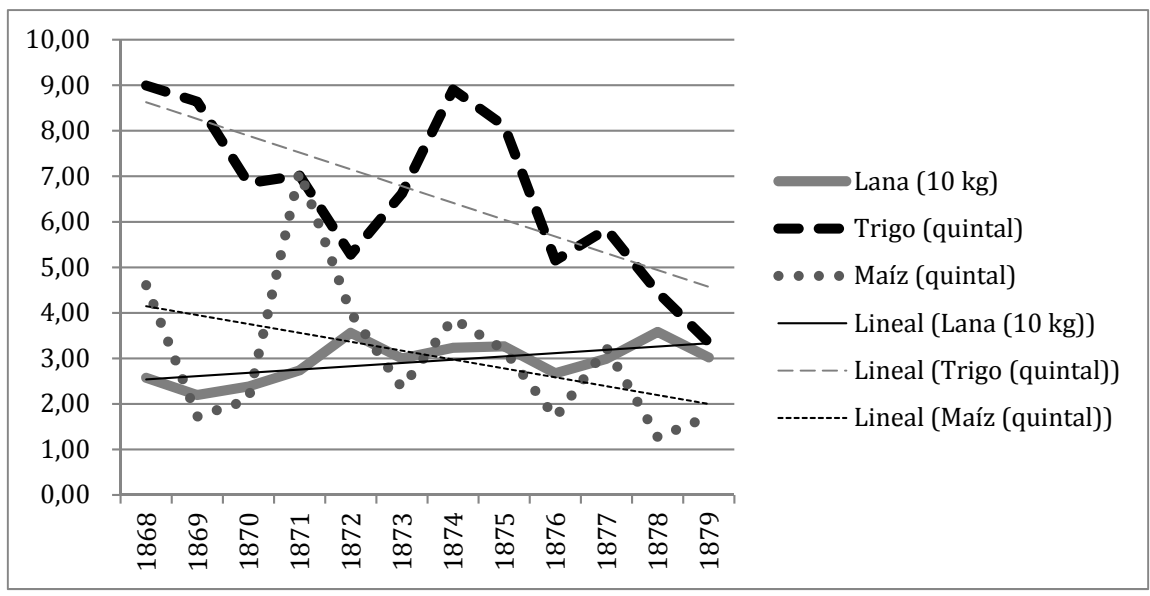

Fuente: Elaboración propia basada en «Series históricas de precios de productos agropecuarios», confeccionadas por el ingeniero agrónomo Rodolfo G. Frank (información disponible en http://anav. org.ar/sites_personales/5/).

Indaguemos sobre algunas razones posibles de este nuevo panorama de la década de 1870. El mejor costo de oportunidad de la ganadería ovina parece haber derivado principalmente de dos variables: la evolución de los precios de los productos agropecuarios y las características del costo factorial. Por el lado de los precios, las series disponibles evidencian una tendencia decreciente en los cereales durante la década. La lana, por el contrario, logró precios estables y levemente al alza. Si bien es difícil aseverar que haya sido una razón determinante, existen indicios para pensar que el precio del producto debió de haber jugado un rol importante en el auge del ganado lanar, lo que probablemente a los ojos de los productores podría resumirse en la siguiente disquisición: ¿para qué arriesgarse a producir un bien (cereal) que tenía no solo oferta extranjera, sino también de las colonias de Santa Fe? Más aun, justamente en la década de 1870 estaba produciéndose un importante cambio técnico en la producción triguera santafesina. El crecimiento de la producción en dichos centros agrícolas iba en ascenso y a 
su vez estaba en vías de insertarse de lleno en el mercado internacional de cereales, de modo que para ello debía producir trigos con un determinado piso en términos de calidad que solo podía ser alcanzado mediante la utilización de instrumentos mecanizados de siega y trilla (al menos en trigo, cebada y lino).

Esta coyuntura presenta la otra cara del costo de oportunidad mencionado, esto es, la cuestión factorial. En este sentido era más seguro y mucho menos oneroso (en términos de acceso al capital) para los productores de Chivilcoy volcarse hacia el lanar antes que arriesgar inversiones en más sementeras, cuyo producto estaba sufriendo una desvalorización a nivel mundial. El acceso a las maquinarias para lograr un cereal de calidad implicaba la necesidad de préstamos a mediano o largo plazo que no iban en general en línea con la limitada capacidad crediticia de pequeños o medianos productores: los principales protagonistas de la expansión agrícola chivilconiana. La tierra, por su parte, venía atravesando desde varias décadas un importante ciclo de alza en su precio.

Otras externalidades también pudieron haber tenido algo que ver en dicha coyuntura. En las encuestas del ya citado Código Rural, los productores de Chivilcoy se lamentaban de la importación de harinas extranjeras y entendían que era un obstáculo para el incentivo a la producción, sobre todo en un contexto en el cual la innovación técnica comenzaba a asomar. La llegada del ferrocarril a los pueblos, la introducción del molino a vapor y el desarrollo de barricas para transportar harina permitirían colocar la producción en el mercado de Buenos Aires, pero faltaban muchas cosas y por eso, entre otras cuestiones, solicitaban: mejorar las vías de comunicación, crear mercados centrales y puertos francos, dar seguridad al labrador para el acarreo de su mercadería, organizar hábitos de comercio y erigir tribunales para mediar en cuestiones referidas a la agricultura. Planteaban que si se ceñía a un número determinado de cuadras el área de chacras, nunca se podría competir con los cereales extranjeros. Sumado a ello, en el caso de Chivilcoy el labrador necesitaba más extensión de tierra para no verse en la necesidad de suspender las sementeras, ya que no podían labrar más de tres años seguidos el mismo paraje. ${ }^{26}$ Estos problemas, propios de Chivilcoy, podrían extenderse a todos los distritos cerealeros de la provincia como para pensar las razones por las cuales la agricultura perdía terreno frente a una actividad más dinámica.

26 Barcos, 2013. 
En Santa Fe, otro era el horizonte durante la década de 1870: no existía prácticamente producción ovina con la cual competir, la ganadería bovina era aun tradicional y de escasa capitalización y el acceso a los factores (maquinarias, tierra y mano de obra familiar) estaba dirigido a los pequeños y medianos productores, que eran los protagonistas del avance agrícola. El desarrollo del proceso de colonización santafesino resulta, por tanto, un caso tan paradigmático como interesante para analizar en perspectiva comparativa, ya que fue a contramano de la estructura productiva pampeana, por lo menos hasta la gran expansión de la agricultura en la década de 1880.

Como ya se ha mencionado, las colonias santafesinas tuvieron un derrotero productivo y social totalmente diferente. La instalación desde cero de grupos de inmigrantes sobre territorios improductivos implicó ingentes inversiones en dinero, que en su mayoría estuvieron a cargo de distintos empresarios. En términos de rentabilidad, los resultados fueron muy malos en los años iniciales. Es decir, los efectos de la colonización en términos económicos y de rentabilidad se notarían a mediano o largo plazo. Las tres colonias primigenias instaladas a mediados de la década de 1850 sufrieron demasiados contratiempos hasta su estabilización o, más aun, hasta que evitaron el peligro de la disolución, no dejando más que pérdidas financieras a sus mentores. ${ }^{27}$

Para ese entonces se trataba aun de un esquema de producción diversificado, a través del cual los colonos tomaban como prioritaria la necesidad de abastecer su grupo doméstico antes que expandirse sobre mercados regionales. Ese esquema se había profundizado sobre todo porque ese tipo de producción con salida mercantil hubiera significado para dichos colonos un riesgo demasiado alto. Así, la diversificación estaba íntimamente imbricada con el momento, el propio planteamiento del fenómeno, y con la falta de medios de comunicación accesibles, rápidos y baratos para grandes volúmenes de productos agrícolas que les pudieran permitir alcanzar los grandes mercados de consumo. ${ }^{28}$

No obstante, el modelo diversificado comenzaría a avizorar señales de agotamiento a fines de la década de 1860 . Se hacía evidente la necesidad de una flexibilidad mucho mayor en el otorgamiento de superficies, y estaba ya muy claro que la producción intensiva diversificada perdía terreno por sus altos costos, la competencia, las dificultades del transporte, y la

27 En el mapa 1, armado en escala, puede notarse el limitado espacio que las colonias santafesinas ocupaban en territorio provincial hacia 1862.

28 Djenderedjian et al., 2010; Martirén, 2016, cap. 2. 
posibilidad de acceder a mercados ampliados más lejanos con producción mercantil especializada y en gran escala. Fue justamente en ese momento cuando estalló la Guerra del Paraguay (1865-1870), la cual terminó por convertir a la zona de colonias en proveedoras de los ejércitos en pugna. ${ }^{29}$ Por causa de su posicionamiento cercano al puerto de Santa Fe, las colonias se volcaron a abastecer ese mercado, particularmente con maíz, cuyo precio se disparó desde 1866. Este acontecimiento habría de convertirse en un punto de inflexión para el proceso de colonización, abriendo un nuevo abanico de posibilidades tanto para los colonos ya establecidos, como para los que formaron parte de nuevas corrientes inmigratorias que arribaron entre 1867 y 1870 .

El auge económico forjado por la guerra mostró, por un lado, que ya existían importantes nichos de producción de granos en las colonias a la par de su matriz diversificada. Y por otro, impulsó el proceso de incorporación de tecnología que cambiaría el modelo productivo local, dejando de tener un patrón diversificado y orientándose hacia la especialización cerealera. Así, para 1872 ya se había extendido el uso de arados más complejos y las máquinas de segar. Este último instrumento resulta clave en la identificación de los avances tecnológicos, en tanto se vuelve fundamental en la optimización de los tiempos del trabajo, al reemplazar al siempre costoso y lento trabajo del cortado de las plantaciones con hoces o guadañas. Tal como se puede notar en la tabla 2, la incorporación de maquinaria redundó en la expansión de la agricultura.

En algo más de quince años, las colonias crecieron en número y en población. Aunque lo más importante en este punto es el efecto del quiebre tecnológico, materializado en la incorporación de arados extranjeros (o copias de estos fabricados en las colonias), más las segadoras, y en menor medida las trilladoras mecánicas. Los datos son realmente sorprendentes en este punto: las 15 segadoras que existían en 1865 habían aumentado a 348 en 1872 , a 541 en 1876 y a 1.790 cinco años después. La nueva maquinaria permitió también el considerable aumento de la superficie sembrada, que para 1876 estaba cubierta por trigo en un $80 \%$. El cambio tecnológico se materializaba en un dato concreto: solo en el departamento Las Colonias las sementeras de trigo se multiplicaron por 30 entre 1865 y 1881 . Más aun, este ciclo de importante crecimiento solo sería el punto de partida de

29 La guerra del Paraguay fue un acontecimiento bélico que enfrentó a una alianza conformada por Argentina, Brasil y Uruguay, contra Paraguay. Tuvo una duración de cinco años, entre 1865 y 1870. 
un proceso que adquiriría un frenético ritmo de crecimiento desde ese momento hasta 1895, con la expansión de este modelo por todo el territorio provincial.

\section{TABLA 2}

EVOLUCIÓN DEMOGRÁFICA Y PRODUCTIVA DEL DEPARTAMENTO LAS COLONIAS

\begin{tabular}{|l|c|c|c|c|}
\cline { 2 - 5 } \multicolumn{1}{c|}{} & \multicolumn{4}{c|}{ Años } \\
\cline { 2 - 5 } \multicolumn{1}{c|}{} & 1865 & 1872 & 1876 & 1881 \\
\hline Cantidad de Colonias & 3 & 9 & 14 & 23 \\
\hline Habitantes & 4.093 & 6.547 & 9.236 & 18.908 \\
\hline Extensión (ha) & 36.820 & $82.397,80$ & $120.557,30$ & $\mathrm{n} / \mathrm{d}$ \\
\hline Ext. Cultivada con Trigo (ha) & 1.600 & $\mathrm{n} / \mathrm{d}$ & $42.154,14$ & 48.825 \\
\hline Cosecha (toneladas) & 2.266 & 12.223 & 14.170 & 53.700 \\
\hline Arados (unidad) & 550 & 1.569 & 2.709 & 5.302 \\
\hline Segadoras (unidad) & 15 & 280 & 541 & 1.790 \\
\hline Trilladoras a vapor o yegua (unidad) & 2 & 7 & 17 & 22 \\
\hline
\end{tabular}

Fuente: Elaboración propia basada en Perkins (1865), Wilcken (1873, anexo), Larguía (1876, anexo) y Aragón (1881, anexo).

\section{El auge de la agricultura extensiva (1881-1895)}

Es sabido que la agricultura pampeana experimentó una enorme expansión desde las últimas dos décadas del siglo XIX. ${ }^{30}$ Este proceso, que tendría un primer freno con la contracción de la demanda generada por el inicio de la Primera Guerra Mundial, había comenzado a sentar sus bases en la década de 1870. En esos años se lograron los progresos tecnológicos que permitieron el desarrollo de una agricultura extensiva y adaptada a los estándares de calidad del producto necesarios para participar en el mercado mundial de cereales. ${ }^{31}$ Un proceso en el que las colonias santafesinas jugaron un rol fundamental, en tanto expandieron su agricultura a través de una receta productiva basada en la incorporación de mejoras técnicas en las

30 Este fenómeno ha sido ampliamente tratado por la literatura académica. Entre los avances historiográficos más recientes que han estudiado el fenómeno se destacan: Míguez, 2008; Barsky y Gelman, 2009; Djenderedjian et al., 2010; Hora, 2010.

31 Sobre el cambio tecnológico en la agricultura pampeana, ver Djenderedjian et al., 2010. 
prácticas de cultivo (utilización de nuevas semillas, manejo de barbechos, control de plagas) y de maquinaria mecanizada sobre todo en los procesos de siega y trilla de cultivos como el trigo, la cebada y el lino. ${ }^{32}$ En Buenos Aires, por el contrario, vimos que la agricultura no tuvo un evidente crecimiento durante esa década. Si bien las estadísticas al respecto son muy dispersas, en el apartado anterior buscamos presentar evidencias que dieran cuenta de un proceso creciente de la ganadería ovina en detrimento de la agricultura, incluso en los distritos de impronta cerealera como Chivilcoy.

Para las décadas de 1880 y 1890, esta endeblez de la información ya no exhibe tantos inconvenientes para realizar un ejercicio comparativo entre ambas provincias. De este modo, en los gráficos 3 y 4 presentaremos cifras de producción agropecuaria de los años 1881, 1888 y $1895 .{ }^{33}$

\section{GRÁFICO 3}

\section{EVOLUCIÓN DEL TOTAL DE LA SUPERFICIE SEMBRADA EN LOS DISTRITOS ANALIZADOS Y EN LAS PROVINCIAS DE BUENOS AIRES Y SANTA FE (1881, 1888 Y 1895, EN HECTÁREAS)}

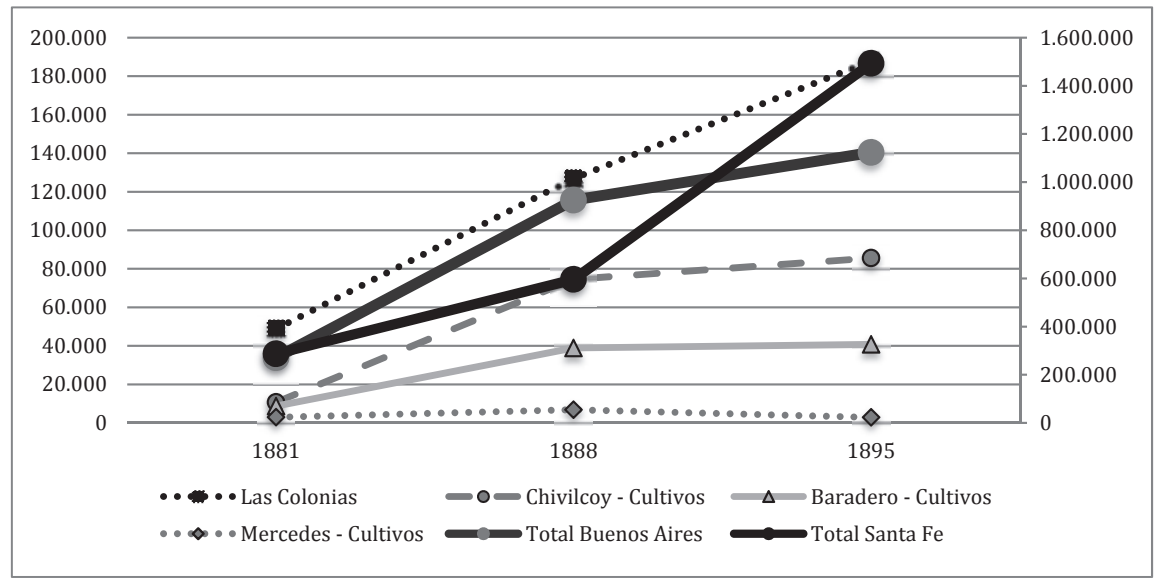

32 Para el caso de la provincial de Santa Fe, ver Martirén, 2016.

33 Se adoptó el año 1881 debido a que ese año se realizó un censo económico-social en la provincia de Buenos Aires, y en las colonias la inspección anual realizada por el gobierno provincial. El año 1888 fue elegido debido a un censo agrícola-ganadero realizado a nivel nacional, cuyos datos fueron sistematizados por Francisco Latzina. En 1895 se realizó el primer censo económico-social a nivel nacional, una fuente clave también para la elaboración de varias estadísticas. Fuentes de ambos gráficos: Elaboración propia basada en: Provincia de Buenos Aires (1883), Aragón (1881), Latzina (1889) y República Argentina (1898). 


\section{GRÁFICO 4}

EVOLUCIÓN DE LA GANADERÍA VACUNA Y OVINA EN LOS DISTRITOS

ANALIZADOS (1881, 1888 Y 1895, EN UNIDADES)

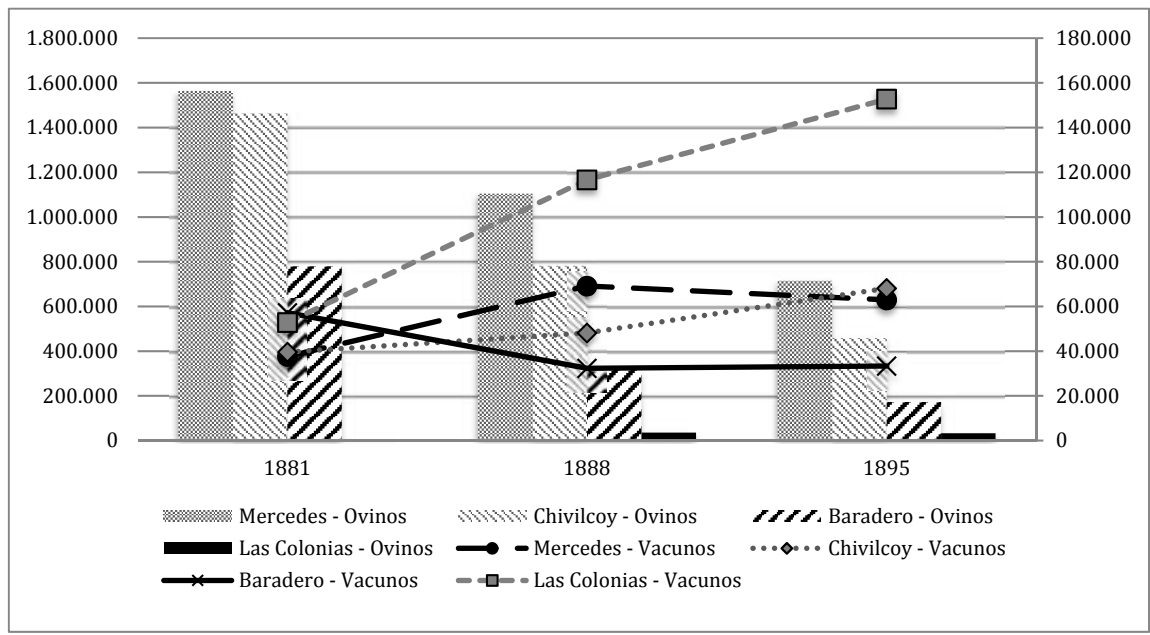

Vale destacar, en primer lugar, que el auge o despegue de la agricultura pampeana presenta, nuevamente, diferencias en ambas provincias. Por el lado santafesino, queda claro que las colonias no solo fueron emprendimientos racionalmente planificados para promover la agricultura, sino que efectivamente lo hicieron en forma progresiva durante todo el período analizado. En Buenos Aires, por su parte, si bien hubo un importante crecimiento de la agricultura, el proceso fue mucho más complejo porque existieron matices y cambios tanto en relación con el otro rubro dinámico (la ganadería vacuna refinada, que también comenzó a ganar espacio ante el declive del lanar) como con respecto a la distribución espacial de la actividad agrícola.

Veamos primero los casos estudiados en detalle: en Chivilcoy los datos de 1881 resultan sorprendentes, pues las 10.690 hectáreas sembradas en 1881 contrastan mucho con las casi 18.500 declaradas en 1864 (suponiendo que estas cifras hayan sido válidas). Este declive se explicaría por la mencionada reconversión hacia el lanar de la década de 1870 ya explicada, y serviría para dar cuenta de los efectos que tuvo el auge de la ganadería ovina sobre la agricultura bonaerense. No obstante, entre 1881 y 1888 el 
panorama cambiaría radicalmente o, para decirlo más concretamente, se invertiría. Tal como se evidencia en el gráfico 3, los años ochenta marcaron una gran expansión de la superficie sembrada en Chivilcoy y Baradero, que a la vez fue acompañada por una destacada caída en las existencias de ovinos. Esto desde luego no se dio en Mercedes, que solo contaba con su producción ejidal, y por ello logró un desempeño muy menor y lineal en todo el lapso estudiado (1881-1895).

Ahora bien, lo interesante de los dos primeros casos aludidos es que su tendencia de crecimiento coincidió con el total de la provincia. La similitud de las curvas tiene una explicación lógica: el auge del cultivo del maíz. La provincia de Buenos Aires pasó de tener 101.000 hectáreas sembradas con ese cereal en 1881 a casi 500.000 en 1888 , lo que implica un crecimiento exponencial. Si bien frenaría algo su tendencia ascendente entre 1888 y 1895 (probablemente por una cuestión de espacio, ya que el maíz era mucho más apto para su cultivo en la zona norte de la provincia y parte del oeste), impulsaría de todos modos el crecimiento de las sementeras bonaerenses. Al adicionar al análisis el comportamiento de los vacunos, puede notarse también que su crecimiento en el período no parece explicar completamente la caída de los ovinos. Según esta evidencia, la agricultura bonaerense, y sobre todo maicera, habría sido la variable responsable. De todos modos, es altamente probable que en esa gran expansión maicera haya influido el proceso de cambio técnico en las razas vacunas que estaba desarrollándose en varios distritos de la provincia de Buenos Aires. La incorporación de nueva genética - mayormente de origen británico- en los planteles ganaderos no solo generó modificaciones sustanciales en la calidad de los vacunos, sino también importantes cambios en toda la cadena productiva del vacuno, entre ellas el tipo de raciones y suplementos, en los cuales el maíz pudo haber tenido importancia. ${ }^{34}$

El trigo, por lo demás, tendría un crecimiento destacado en dicha provincia, aunque mucho más sobrio que en Santa Fe, donde el esquema de colonización y especialización cerealera tenía a este cereal, a la cebada y al lino como cultivos principales. Puede notarse así que el período 1888-1895 fue sin dudas la «época de oro» de la agricultura santafesina, impulsada por la agricultura en colonias, que durante ese período terminaría por monopolizar el territorio cultivable de la provincia (esto puede verse claramente en el mapa 2).

34 Ver al respecto Sesto, 2005. 


\section{MARÍA FERNANDA BARCOS Y JUAN LUIS MARTIRÉN}

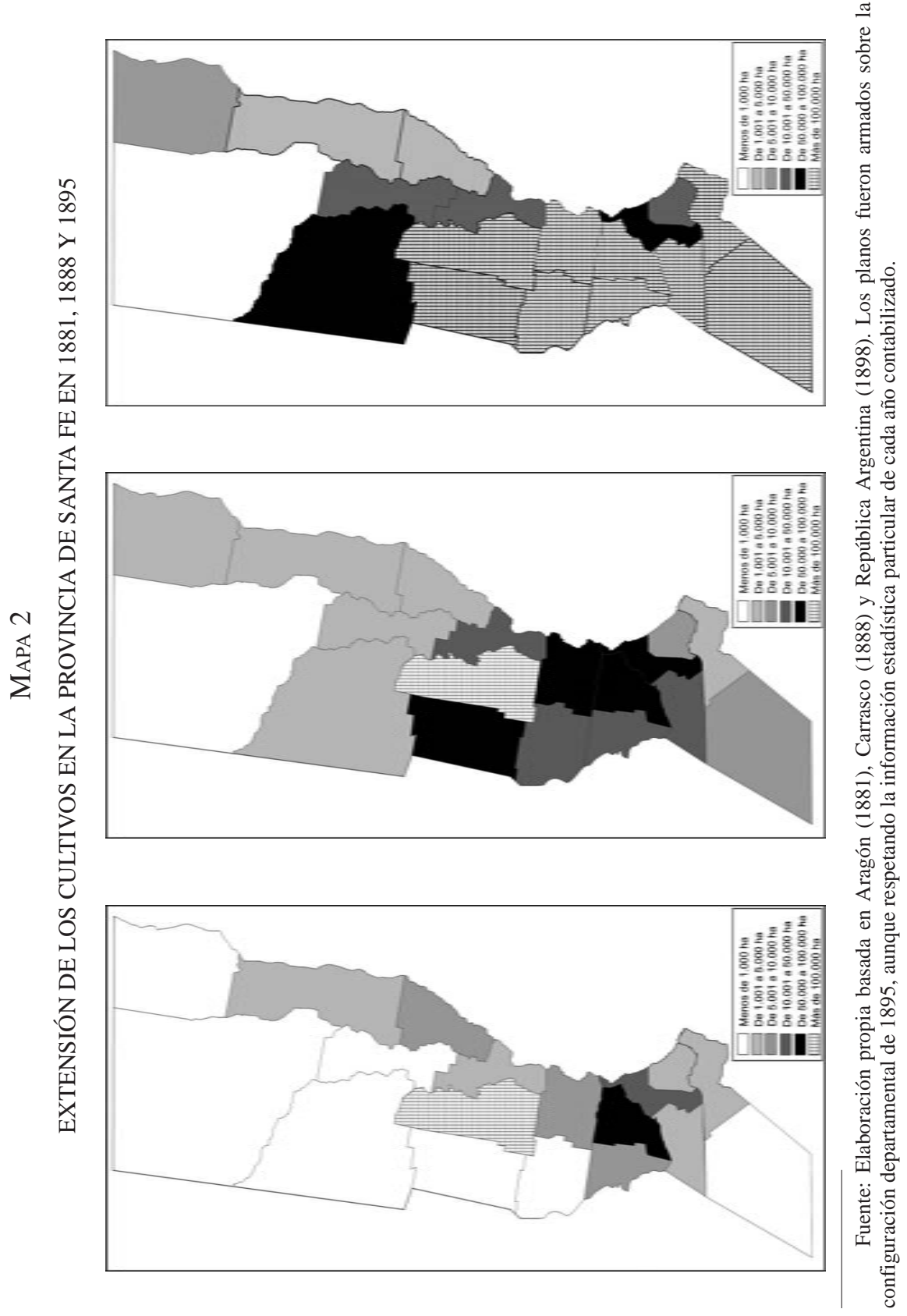


En otro orden, es indudable que este nuevo contexto de crecimiento fue motorizado por la expansión de la agricultura «a campo» o extensiva en ambas provincias. En Santa Fe, como mencionamos antes, las colonias replicaron su receta a partir de una configuración territorial que permitía realizar agricultura de escala (las unidades productivas promedio tenían entre 100 y 250 hectáreas). ${ }^{35}$ En Buenos Aires, mientras tanto, el sistema ejidal comenzó a perder peso en el total productivo. A inicios de la década de 1880 se buscó subsanar los problemas de este tipo de agricultura con medidas de ensanches de ejidos. Esto ocurrió en varios partidos (entre ellos, los tres distritos bonaerenses aquí analizados) con la intención de ampliar la zona de quintas y chacras, que se encontraba constreñida por el crecimiento de los centros poblados y las estancias ganaderas. Sin embargo, muchos de estos ensanches no cumplieron con el objetivo de incentivar a los agricultores, puesto que no solo el alto valor de los terrenos fue un obstáculo para los pequeños productores, sino que la extensión de estas unidades no permitía la agricultura a gran escala. Esto mostró una vez más que la solución a la expansión de la agricultura bonaerense se encontraba más en la ampliación de la escala que en la difusión de los ejidos.

Con ese modelo de agricultura «a campo», Chivilcoy logró recuperar nuevamente su polo agrícola, e incluso replicarlo en los partidos aledaños. Como se desprende del mapa 3, la agricultura se había asentado con fuerza. A diferencia de Santa Fe, donde el esquema de colonización fue el responsable de la expansión de la frontera, en Buenos Aires la privatización de la tierra pública y el proceso de ocupación de nuevos territorios fue más heterogénea, con un peso mucho mayor de medianas y grandes unidades de producción en su estructura agraria. Estos establecimientos, que hasta la década de 1870 se habían volcado casi con exclusividad a la ganadería, comenzaron a diversificar su producción, particularmente con la intención de mejorar sus pasturas para expandir la cría de ganado refinado. ${ }^{36}$

35 Sobre el promedio de las unidades de explotación, ver Gallo, 1983; Djenderedjian et al., 2010, v. 2.

36 Es de destacar que este proceso de diversificación vino de la mano de un fenómeno fundamental: el crecimiento demográfico y el afluente inmigratorio europeo que tuvo la campaña de Buenos Aires, acelerado desde la década de 1880. La disponibilidad de brazos para las faenas rurales crecería y cambiaría completamente la ecuación de los emprendimientos agrarios y de la dotación de factores. No podemos explayarnos en este tema por motivos de espacio, pero es importante remarcar que los efectos que la inmigración masiva tuvieron sobre el factor mano de obra fueron centrales a la hora de expandir la agricultura bonaerense. 


\section{MARÍA FERNANDA BARCOS Y JUAN LUIS MARTIRÉN}

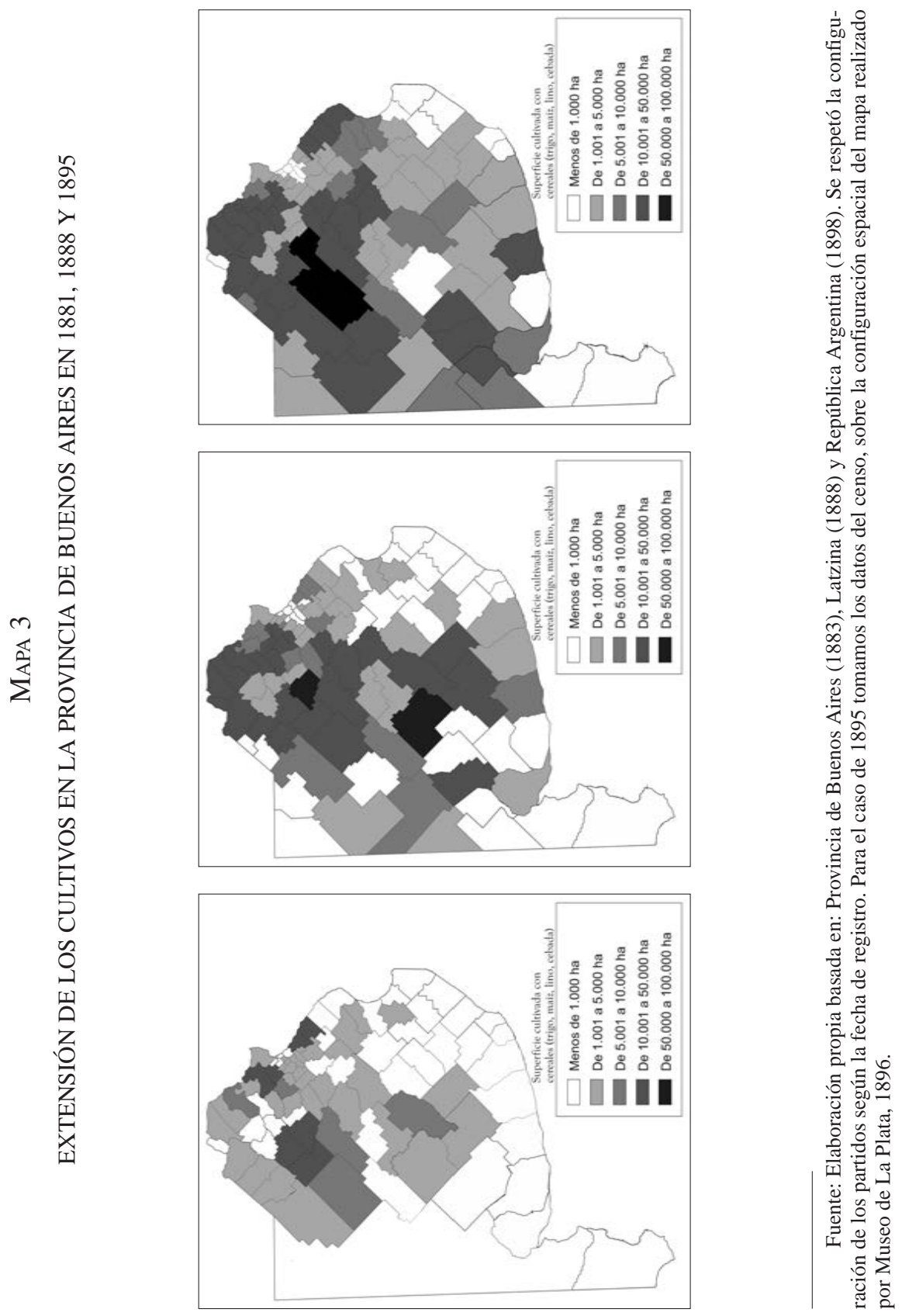


De esta manera, la expansión de la agricultura comenzó a ganar espacio en nuevos territorios de frontera, teniendo como epicentro los distritos cerealeros más antiguos. Este proceso de expansión hacia el oeste y el sur provinciales fue posible también gracias a la extensión de las líneas férreas, que lograron hacer efectiva la receta extensiva aun en territorios donde el costo de los fletes con tracción a sangre no hacía lucrativa la producción de cereales. Así, la llegada del ferrocarril, que había sido central para la expansión del ovino en décadas pasadas, favoreció esta vez el desarrollo agrícola.

El año 1895 marcaría el auge de la agricultura pampeana, tanto en Santa Fe como en Buenos Aires. Un camino más lineal había recorrido en Santa $\mathrm{Fe}$, donde la agricultura no debió competir con otras actividades que generaran un desbalance en el costo de oportunidad. En Buenos Aires, por el contrario, esto fue muy claro sobre todo en la década de 1870, aunque en el epílogo del siglo estas dificultades eran poco más que un recuerdo, no solo porque la provincia había logrado asentar su receta, sino porque iba en camino a convertirse (por lejos) en poco tiempo más en el principal distrito cerealero del país.

\section{Conclusiones}

Hacia 1880, la agricultura pampeana había alcanzado importantes transformaciones, materializadas sobre todo en las décadas de 1860 y 1870. Operó en ese período un cambio técnico que tuvo diferentes repercusiones según el espacio. La otrora considerable producción agrícola bonaerense, que había logrado consolidar destacados centros de producción de granos en la campaña ya desde la época colonial, comenzó un sendero decreciente en términos relativos, frente a un novedoso experimento agrario que iba cobrando fuerza en la provincia de Santa Fe, las colonias agrícolas. Varios son los motivos de estas mudanzas, y sobre algunos de los cuales buscamos problematizar en este trabajo. En primer lugar, el declive de la producción agraria bonaerense tradicional se debió en gran medida a la propia dotación local de factores. Con la emergencia del auge lanero desde mediados de la década de 1840, esta actividad se volvió un competidor muy activo sobre la agricultura en términos de rentabilidad. Impulsó a la vez un proceso creciente de alza de precios de la tierra, y ambos dificultaron la actividad agrícola. Para poder expandirse, la agricultura necesitaba indefectiblemente ciertos pisos en la escala de las unidades de producción que la tradicional 
estructura agraria ejidal no podía ofrecer, ya que no solo se realizaba en unidades muy pequeñas, sino que también sufría el costo del transporte y la competencia extranjera. Sumado a esto, los costos de mano de obra adicional y el rol de los otros actores — por ejemplo los panaderos- dificultaba el esquema productivo. Así, las mejoras técnicas, que quedaron limitadas básicamente a la agricultura «a campo», no lograron ir paralelamente a las aplicadas en la ganadería ovina, que crecieron a un ritmo diferencial y generaron niveles de rentabilidad probablemente más altos.

En las colonias, por su parte, el proceso de cambio técnico no tuvo que enfrentar los obstáculos propios de la competencia con otras actividades, ya que el avance de la colonización se hizo sobre tierras yermas o bien de baja rentabilidad, con escasa existencia de conflictividades legales al respecto. Sumado a ello, su propio crecimiento fue propiciado tanto por la implantación de un esquema productivo particular, como por el desarrollo de un soporte institucional y financiero propio que le permitió retroalimentarse. De este modo, las colonias tuvieron ventajas para aplicar el método del ensayo y error y también financiación extra para incorporar nueva tecnología en maquinaria, que redundó muy pronto en resultados concretos de crecimiento económico y productivo.

Con estos resultados, no resulta llamativo encontrar que para 1881 no solo la agricultura cerealera santafesina ya se posicionaba para desplazar en general a Buenos Aires (de hecho, ya la superaba ampliamente en términos de producción per cápita), sino que distritos anteriormente destacados como Chivilcoy contaban con menores niveles de inversión en maquinaria y de producción relativa que los centros agrícolas santafesinos.

Sin embargo, la década de 1880 cambió el panorama, en particular el bonaerense. El declive de la ganadería ovina parece haber facilitado el desarrollo de la agricultura, que logró un crecimiento exponencial entre 1881 y 1888 , impulsada por el auge del maíz. El cambio no se logró mediante la tradicional agricultura ejidal - ahora consolidada como un espacio de abasto interno de frutas, hortalizas y combustible junto con establecimientos variados como fábricas de ladrillos, tambos, atahonas, molinos-, sino que fue impulsado por la agricultura extensiva «a campo», un esquema que ya había mostrado sus ventajas en Santa Fe. No obstante, vale destacar que la ampliación de las sementeras de maíz también podría haber estado relacionada con el proceso de refinamiento vacuno. El reemplazo de los tradicionales fenotipos de ganado criollo con puros de raza británica pudo haber impulsado la demanda de maíz como ración suplementaria, generando así 
una sinergia entre grandes productores ganaderos y pequeños y medianos agricultores.

Así, en el epílogo del siglo, las características diferenciales que existían entre Buenos Aires y Santa Fe en términos agrícolas, al menos en las décadas de 1860 y 1870 , se habían atenuado. El crecimiento de la agricultura había adquirido un ritmo frenético, logrando sobrepasar ambas el millón de hectáreas sembradas con cereales. Se habían sentado las bases de una estructura agrícola que seguiría franco ascenso hasta 1914.

Recibido el 11 de septiembre de 2017 Segunda versión el 13 de marzo de 2018 Aceptado el 25 de abril de 2018

\section{Referencias bibliográficas}

Álvarez de Arenales, J., Provincia de Buenos Aires, Buenos Aires, Lit. J. Pelvilain, 1862.

Andreucci, Bibiana, Labradores de Frontera. La Guardia de Luján y Chivilcoy, 1780-1860, Rosario, Prohistoria, 2011.

Aragón, Agustín, Informe de la Inspección de Colonias de la Provincia de Santa Fe hasta 1880, Rosario, Imprenta de R. Carrasco, 1881.

Barcos, M. Fernanda, Pueblos y ejidos de la campaña bonaerense. Una historia sociojurídica de los derechos de propiedad y la conformación de un partido: Mercedes, 1780-1870, Rosario, Prohistoria, 2013.

Barcos, M. Fernanda, «La distribución de la tierra y el crecimiento económico de la campaña de Buenos Aires: Un estudio de la región Oeste, 1839-1867», Secuencia, 101, México, 2018, 6-40.

Barsky, Osvaldo y Djenderedjian, Julio, Historia del capitalismo agrario pampeano. Tomo 1. La expansión ganadera hasta 1895, Buenos Aires, Universidad de Belgrano y Siglo XXI Editores, 2003.

Barsky, Osvaldo y Gelman, Jorge, Historia del agro argentino, Buenos Aires, Sudamericana, 2009.

Beck, Charles, La République Argentine. Manuel de l'émigrant et du cultivateur, Berne, Imprimerie J. Allemann, 1872.

Carrasco, Gabriel, La provincia de Santa Fe. Revista de su estado actual y de los progresos realizados, Buenos Aires, Impr. de Pablo Coni, 1888.

Ciliberto, Valeria, Aspectos sociodemográficos del crecimiento periurbano. San José de Flores (1815-1869), Mar del Plata, UNMdP / GIHRR, 2004.

Djenderedjian, Julio, Historia del capitalismo agrario pampeano. Tomo 4. La agricultura pampeana en la primera mitad del siglo XIX, Buenos Aires, Universidad de Belgrano y Siglo XXI Editores, 2008. 
Djenderedjian, Julio; Bearzotti, Sílcora y Martirén, Juan Luis, Historia del capitalismo agrario pampeano. Tomo 6. Expansión agrícola y colonización en la segunda mitad del siglo XIX, Buenos Aires, Universidad de Belgrano y Teseo, 2010, 2 v.

Estado de Buenos Aires, Rejistro estadístico del Estado de Buenos Aires, año 1855, Buenos Aires, Imprenta Porteña, 1855.

Ford, Francis Claire, La République Argentine, Paris, Laroque Jeune / Bergelot, 1867.

Frid, Carina, «Preludio a la Pampa Gringa: expansión ganadera y crecimiento económico en la provincia de Santa Fe (1840-1870)», trabajo presentado en la Red de Estudios Rurales, Instituto Ravignani, Buenos Aires, 2007, mimeografiado.

Gallo, Ezequiel, «Santa Fe en la segunda mitad del siglo XIX. Transformaciones en su estructura regional», en Di Tella, T. y Halperin Donghi, T. (comps.), Los fragmentos del poder, Buenos Aires, Jorge Álvarez, 1972, pp. 243-273.

Gallo, Ezequiel, La Pampa Gringa, Buenos Aires, Sudamericana, 1983.

Garavaglia, Juan Carlos, «Los labradores de San Isidro (siglos XVIII-XIX)», Desarrollo económico, 128, Buenos Aires, 1993, 514-542.

Garavaglia, Juan Carlos, «La propiedad de la tierra en la región pampeana bonaerense: algunos aspectos de su evolución histórica (1730-1863)», en Fradkin, Raúl y Garavaglia, Juan Carlos (eds.), En busca de un tiempo perdido. La economía de Buenos Aires en el país de la abundancia, 1750-1865, Buenos Aires, Prometeo Libros, 2004, 65-106.

Gelman, Jorge y Santilli, Daniel, De Rivadavia a Rosas: Desigualdad y crecimiento económico, Buenos Aires, Siglo XXI Editores, 2006.

Gelman, Jorge y Santilli, Daniel, «¿Cómo explicar la creciente desigualdad? La propiedad de la tierra en Buenos Aires entre 1839 y 1867», en Gelman, J. (ed.), El mapa de la desigualdad en la Argentina del siglo XIX, Rosario, Prohistoria, 2011, 171-218.

Gelman, Jorge y Santilli, Daniel, «Movilidad social y desigualdad en el Buenos Aires del siglo XIX: el acceso a la propiedad de la tierra entre el rosismo y el orden liberal», Hispanic American Historical Review, 93 (4), Durham, 2013, 659-684.

GIHRR (Grupo de Investigaciones en Historia Rural Rioplatense), «La sociedad rural bonaerense a principios del siglo XIX. Un análisis a partir de las categorías ocupacionales», en Fradkin, R. y Garavaglia, J. C. (eds.), En busca de un tiempo perdido. La economía de Buenos Aires en el país de la abundancia 1750-1865, Buenos Aires, Prometeo, 2004, 21-63.

Hora, Roy, Historia económica de la Argentina en el siglo XIX, Buenos Aires, Siglo XXI Editores, 2010.

Larguía, Jonas, Informe del Inspector de colonias e la Provincia de Santa Fe, Buenos Aires, Imprenta y Litografía del «Courier de La Plata», 1876. 
Latzina, Francisco, L'agriculture et l'élevage dans la République Argentine d'après le Recensement de la première quinzaine d'octobre de 1888 fait sous les auspices de la Commission chargée des travaux de la section argentine a l'exposition de Paris, Paris, Imprimerie Typographique P. Mouillot, 1889.

Martirén, Juan Luis, «Contrastes de Frontera. Farmers y Criollos en los prolegómenos de la gran expansión agraria de la provincia de Santa Fe (1856-1875)», Prohistoria, 22, Rosario, 2014, pp. 81-105.

Martirén, Juan Luis, La transformación farmer. Colonización agrícola y crecimiento económico en la provincia de Santa Fe durante la segunda mitad del siglo XIX, Buenos Aires, Prometeo, 2016.

Míguez, Eduardo, «La expansión agraria de la pampa húmeda (1850-1914). Tendencias recientes de su análisis histórico», Anuario IEHS, 1, Tandil, 1986, 89-119.

Míguez, Eduardo, «¿Veinte años no es nada? Balance y perspectivas de la producción reciente sobre la gran expansión agraria, 1850-1914», en Gelman, J. (comp.), La historia económica argentina en la encrucijada. Balances y perspectivas, Buenos Aires, Asociación Argentina de Historia Económica y Prometeo Libros, 2006, 209-230.

Míguez, Eduardo, Historia Económica de la Argentina. De la Conquista a la crisis de 1930, Buenos Aires, Sudamericana, 2008.

Mulhall, M.G. y E.T., Manual de las Repúblicas del Plata, Buenos Aires, Imp. del «Standard», 1876.

Museo de La Plata, Mapa mural de la Provincia de Buenos Aires, La Plata, 1896.

Perkins, Guillermo, Las colonias de Santa Fe, Rosario, Imp. de El Ferrocarril, 1865.

Provincia de Buenos Aires, Registro Estadístico de la Provincia de Buenos Aires, Año 1862, Tomo Primero, Buenos Aires, Imp. y Lit. a vapor de Bernheim y Boneo, 1864.

Provincia de Buenos Aires, Registro Estadístico de la Provincia de Buenos Aires, Año 1872, Segunda Época: Año Décimo Noveno, Buenos Aires, Imp. de Pablo Coni, 1874.

Provincia de Buenos Aires, Registro Estadístico de la Provincia de Buenos Aires, Año 1873, Segunda Época: Año Vigésimo, Buenos Aires, Imp. de Pablo Coni, 1875.

Provincia de Buenos Aires, Registro Estadístico de la Provincia de Buenos Aires, Año 1874, Segunda Época: Año Vigésimo Primero, Buenos Aires, Imp. de Pablo Coni, 1876.

Provincia de Buenos Aires, Censo general de la Provincia de Buenos Aires, Buenos Aires, Imp. de El Diario, 1883.

República Argentina, Rejistro Estadístico de la República Arjentina, 1864, Tomo Segundo, Buenos Aires, Imp. y, Lit. y Fundición de Tipos a Vapor J. Bernheim, 1865. 
República Argentina, Segundo censo de la República Argentina, Tomo 3, Buenos Aires, Taller Tipográfico de la Penitenciaría Nacional, 1898.

Sábato, Hilda, Capitalismo y ganadería en Buenos Aires: la fiebre del lanar, 18501890, Buenos Aires, Sudamericana, 1989.

Salaberry, Ignacio, Brazos poderosos. Inmigración, agricultura y municipio en el Estado de Buenos Ayres. Creación de la Colonia suiza del Baradero, Buenos Aires, De los Cuatro Vientos, 2009.

Sesto, Carmen, Historia del capitalismo agrario pampeano. Tomo 2. La vanguardia ganadera bonaerense, 1856-1900, Buenos Aires, Universidad de Belgrano y Siglo XXI Editores, 2005.

Sociedad Agrícola de Baradero, Estadística agrícola de la colonia del Baradero, Buenos Aires, Imp. de Pablo Coni, 1882.

Wilcken, Guillermo, Las colonias. Informe sobre el estado actual de las colonias agrícolas de la República Argentina, Buenos Aires, Impr. de la Sociedad Anónima, 1873. 